\title{
BMJ Open Prevalence of major cardiovascular disease risk factors among a group of sub-Saharan African young adults: a population-based cross-sectional study in Yaoundé, Cameroon
}

\author{
Jobert Richie Nansseu (D) , ${ }^{1,2}$ Bibiane Siaheu Kameni, ${ }^{3}$ Felix Kembe Assah, ${ }^{1}$ \\ Jean Joel Bigna (D) , ${ }^{4,5}$ Saint-Just Petnga, ${ }^{6}$ Dahlia Noelle Tounouga, ${ }^{7}$ \\ Shalom Tchokfe Ndoula, ${ }^{8}$ Jean Jacques Noubiap, ${ }^{9}$ Joseph Kamgno ${ }^{1,10}$
}

To cite: Nansseu JR, Kameni BS, Assah FK, et al. Prevalence of major cardiovascular disease risk factors among a group of sub-Saharan African young adults: a population-based cross-sectional study in Yaoundé, Cameroon. BMJ Open 2019;9:e029858. doi:10.1136/ bmjopen-2019-029858

- Prepublication history for this paper is available online. To view these files, please visit the journal online (http://dx.doi. org/10.1136/bmjopen-2019029858).

Received 14 February 2019 Revised 26 August 2019 Accepted 02 September 2019

Check for updates

(C) Author(s) (or their employer(s)) 2019. Re-use permitted under CC BY-NC. No commercial re-use. See rights and permissions. Published by BMJ.

For numbered affiliations see end of article.

Correspondence to Dr Jobert Richie Nansseu; jobertrichie_nansseu@yahoo.fr

\section{ABSTRACT}

Objective To determine the prevalence estimates of some major risk factors for cardiovascular disease (CVD) in a young adult-aged population living in Yaoundé, Cameroon. Design A cross-sectional study held from May to July 2017. Setting

Participants Students aged 18-35 years, with no known history of CVD, found at the campus during recruitment and who voluntarily agreed to be included in the study. Primary and secondary outcome measures Data were collected on personal and family history as well as lifestyle and nutritional habits; anthropometric parameters and blood pressure were also measured. Prevalence rates were calculated with their respective $95 \% \mathrm{Cl}$.

Results Overall, 931 participants (53.8\% males) were included, with a median age of 23 years (IQR 21-25). The prevalence estimates for some major CVD risk factors were: $3.1 \%(95 \% \mathrm{Cl} 2.0$ to 4.2$)$ for family history of heart attack, $6.3 \%(95 \% \mathrm{Cl} 4.7$ to 7.9$)$ for family history of stroke, $26.7 \%$ (95\% Cl 23.9 to 29.5) for hazardous alcohol consumption, $0.9 \%$ (95\% 0.3 to 1.5 ) for current tobacco smoking, $27.6 \%$ (95\% Cl 24.7 to 30.5$)$ for secondhand smoking, $88.9 \%$ (95\% Cl 86.9 to 90.9$)$ for physical inactivity, $99.0 \%$ (95\% Cl 98.4 to 99.6$)$ for inadequate fruits and/or vegetables consumption, $39.8 \%(95 \% \mathrm{Cl}$ 36.7 to 42.9$)$ for self-reported anxiety, $49.2 \%(95 \% \mathrm{Cl}$ 46.0 to 52.4 ) for self-reported depression, $22.1 \%$ (95\% Cl 19.4 to 24.8$)$ for overweight, $3.9 \%(95 \% \mathrm{Cl} 2.7$ to 5.1$)$ for obesity, $14.4 \%$ (95\% Cl 12.1 to 16.7$)$ for abdominal obesity, $14.5 \%$ (95\% Cl 12.2 to 16.8) for excess body fat mass, $30.0 \%$ (95\% Cl 27.1 to 32.9$)$ for suspected prehypertension and $2.8 \%$ (95\% $\mathrm{Cl} 1.7$ to 3.9$)$ for suspected hypertension.

Conclusion The prevalence of some major CVD risk factors is high among young adults living in Yaoundé, Cameroon. Therefore, specific actions should be undertaken in this population to mitigate the upcoming burden of CVD. Accordingly, younger-aged adult populations should be encouraged and accompanied to practice physical activity, eat healthily, and stop or avoid smoking and/or hazardous alcohol consumption.
Strengths and limitations of this study

- This study evaluated the burden of major cardiovascular disease (CVD) risk factors in a group of youngadult Cameroonians.

- This was a population-based study, permitting to have an estimate of the real burden of CVD risk factors, as compared with a hospital-based study which would have presumably led to overestimations.

- A consecutive and non-probabilistic sampling procedure was used; hence, the results may not be generalised to the entire population of young-adult Cameroonians.

- There might have been some information bias, as a consequence of the fact that some parameters were self-reported.

\section{INTRODUCTION}

Cardiovascular disease (CVD) is one of the leading causes of morbidity and mortality worldwide. It is estimated that about 17.9 million of people die every year due to CVD, which constitutes around $31 \%$ of all global deaths. Most of these CVD-related deaths are caused by heat attack and stroke, in about $85 \%$ of cases. ${ }^{12}$ Although current trends indicate a decrease in the burden of CVD in developed countries, the condition is still increasing globally and reaching epidemic proportions, especially in the developing world where almost $80 \%$ of cardiovascular-related deaths occur. ${ }^{3-7}$ This is mainly driven by low rates of awareness, treatment and control of major CVD risk factors. ${ }^{8}$

CVD has a long life-course evolution with its main risk factors starting as early as in childhood, adolescence or young adulthood..$^{9-13}$ CVD can be prevented by addressing behavioural risk factors which include eating 
food with high salt concentration and low fruits and vegetables, low and inadequate physical activity, tobacco smoking and harmful use of alcohol. Furthermore, many people who are at higher cardiovascular risk with the presence of elevated blood pressure (BP), elevated blood glucose, high blood cholesterol, overweight and obesity need early detection and overall proper management to reduce the likelihood of CVD occurrence. ${ }^{12}$

In line with 'Global Hearts', an initiative from the WHO and its partners to beat back the global threat of $\mathrm{CVD},{ }^{14}$ efficient and evidence-based interventions have to be initiated in younger populations to delay or prevent CVD occurrence in adulthood. However, their development requires having the current figures of the burden of CVD risk factors in these populations. Accordingly, the present study was designed, which purposed to determine the prevalence estimates of major risk factors for CVD in a young adult-aged population living in Yaoundé, Cameroon (a developing country).

\section{METHODS}

\section{Study design and setting}

From May to July 2017, a cross-sectional, urban-based and population-based study was carried out at the main campuses of the University of Yaoundé I, Cameroon. Situated in Yaoundé the capital city of Cameroon, this academic institution represents the oldest and biggest university in-country, with its students coming from all the 10 administrative regions of Cameroon.

\section{Study participants}

Any apparently healthy university student aged between 18 and 35 years, regularly registered at the University during the academic year 2016-2017, with no known history of CVD, found at the Yaoundé University campuses during recruitment and who voluntarily agreed to be included in the study was enrolled. Pregnant women or those breastfeeding were not considered in this study. Participants were consecutively recruited during the study period, using a non-probabilistic consecutive sampling method. The minimal sample size was calculated based on Krejcie and Morgan's formula: $S=Z^{2 *} N^{*} P *(1 P) /\left[d^{2 *}(N-\right.$ $\left.1)+Z^{2} * P *(1 P)\right] .{ }^{15}$ Accordingly, the CI was fixed at $95 \%$, hence $Z^{2}=1.96$ and $d=0.05$. The population proportion with global risk factors for CVD was assumed to be 0.5 since this would provide the maximum sample size. Considering a population size of 73607 students regularly registered in the study site during the academic year $2016-2017,{ }^{16}$ the minimal sample size was calculated at 382 subjects.

\section{Data collection}

Data were collected using a standardised, anonymous, pretested and partly self-administered questionnaire. It was essentially composed of two main sections: identification (sociodemographic characteristics) and medical history (family and personal medical history, and lifestyle habits). On the days of recruitment, potential participants who were found on various campuses of the University were approached by the research team. After presenting the various aspects and procedures in relation with the study, those who volunteered to be enrolled signed a consent form. Subsequently, they filled the questionnaire and underwent a brief physical examination during which anthropometric parameters (weight, height, fat mass percentage, mid-upper arm, waist and hip circumferences) and BP were measured. At the end of this process, every participant received adequate counselling considering his/her parameters, principally directed towards heathy lifestyle habits. For those who were found with an abnormality, they were referred to the Medical and Social Welfare Centre of the University for further investigations and adequate care.

Alcohol consumption was assessed using the Alcohol Use Disorder Identification Test-Consumption (AUDIT-C) score; accordingly, hazardous alcohol drinking was considered on the basis of an AUDIT-C score $\geq 4$ for men, and $\geq 3$ for women. ${ }^{17}{ }^{18}$ Smoking status was classified as never, former (last smoked $>12$ months ago) and current (ever smoked in the last 12 months). Secondhand smoking was defined as regular exposure to other people's smoke over the last 12 months, and measured in hours per week. Similarly, household air pollution was assessed through exposure to firewood smoke, and also measured in hours per week. Physical activity was evaluated with the Global Physical Activity Questionnaire, and classified into four groups: 'mainly sedentary' (if the participant was not used to performing any physical activity, especially during leisure time); 'mild exercise' (easy walking for at least 10 min continuously several times in a week or moderate/ strenuous exercise but not responding to the recommendations); 'moderate exercise' (any activity inducing a small increase in breathing or heart rate, performed during at least $30 \mathrm{~min}$ and at least 5 days/week); 'strenuous exercise' (any activity causing a large increase in breathing or heart rate, performed during at least $25 \mathrm{~min}$ and at least 3 days/week). ${ }^{19} 20$ Adequate fruits intake was defined as a daily consumption of 1.5-2 portion/cup equivalents of fruits while adequate vegetables intake was based on a consumption of 2-3 cups of vegetables, daily. ${ }^{21}$

Height was measured to the nearest $0.5 \mathrm{~cm}$ using a stadiometer. Weight (to the nearest $0.1 \mathrm{~kg}$ ) and fat mass percentage were measured with a body composition analyzer (type BPF-300 MA, Tanita UK, Yiewsley, Middlesex, UK). Body mass index (BMI) was derived as weight (kg)/ height $\mathrm{t}^{2}\left(\mathrm{~m}^{2}\right)$ and subsequently grouped into four categories: underweight $(<18.5)$, normal (18.5-24.9), overweight (25.0-29.9) or obese $(\geq 30.0){ }^{22}$ Excess body fat mass was defined if the fat mass percentage was $>20 \%$ for men and $>33 \%$ for women, according to cut-offs given by the body composition analyser. Mid-upper arm, waist and hip circumferences were measured to the nearest $0.1 \mathrm{~cm}$ with a measuring tape. Waist to hip ratio (WHR) was calculated as waist circumference (WC) $(\mathrm{cm})$ divided by hip circumference $(\mathrm{cm})$. Abdominal obesity was defined using three 
criteria : (1) according to the International Diabetes Federation (IDF) criteria, WC $>90 \mathrm{~cm}$ for men and $>80 \mathrm{~cm}$ for women; (2) according to the WHO criteria, WC $>102 \mathrm{~cm}$ for men and $>88 \mathrm{~cm}$ for women; (3) according to the WHO criteria, WHR $\geq 0.9$ for men and $\geq 0.85$ for women. ${ }^{23}$

An electronic sphygmomanometer (Omron M5-1, Omron Healthcare, Kyoto, Japan) was used for BP measurement. The participant rested for at least $5 \mathrm{~min}$ at a sitting position. $\mathrm{BP}$ was measured thrice on the left arm at a $5 \mathrm{~min}$ interval, and the mean of these three measurements was considered for further analyses. Suspected hypertension was defined on presence of a systolic blood pressure (SBP) $\geq 140 \mathrm{~mm} \mathrm{Hg}$ and/or a diastolic blood pressure (DBP) $\geq 90 \mathrm{~mm} \mathrm{Hg}$ and/or self-reported history of antihypertensive medication. The participant was suspected of prehypertension on presence of a SBP between 120 and $139 \mathrm{~mm}$ $\mathrm{Hg}$ and/or a DBP between 80 and $89 \mathrm{~mm} \mathrm{Hg.}{ }^{24}$ This suspicion was based on the fact that students were not seen at further occasions to have their BP retaken, to confirm or refute the diagnosis of prehypertension/hypertension.

\section{Statistical procedures}

SPSS V.20.0 served for data analysis. For continuous variables and due to skewed distributions, results were presented as median (IQR) and comparisons used non-parametric tests (Mann-Whitney U test or Kruskal-Wallis $\mathrm{H}$ test). Furthermore, strength and direction of a monotonic relationship between continuous variables were investigated using the Spearman correlation test and its rho $(\rho)$ coefficient. Categorical variables were summarised with frequencies (percentages) and tested using the $\chi^{2}$ test or Fisher exact test, where applicable. Results were considered statistically significant for a $\mathrm{p}$ value $<0.05$.

\section{Ethical considerations}

Before starting this study, a study protocol was conceived and designed, and submitted to the Cameroon Bioethics Initiative Ethics Review and Consultancy Committee for ethical approval. Once the ethical clearance was granted (reference CBI/404/ERCC/CAMBIN), an administrative authorisation was requested and further delivered by the Rector of the University of Yaoundé I. Study procedures complied with the revised Helsinki Declaration. After presenting and explaining all aspects and procedures to each potential participant, those who voluntarily accepted to participate signed a consent form, accordingly. Participation was kept anonymous, and information gathered, confidential.

\section{Patient and public involvement}

Participants and the public were not involved in the design, conduct and reporting of this research.

\section{RESULTS}

Sociodemographic background of the study population

Nine hundred and thirty-one students (53.8\% males) participated in this study. Their ages ranged from 18 to 35 years with a median of 23 (IQR 21-25) years. According to table 1 , majority of students were aged $21-25$ years $(55.4 \%)$, were Christians by faith $(89.8 \%)$ and were single $(93.3 \%)$.

\section{Burden of major CVD risk factors}

Table 2 depicts the prevalence estimates of some major CVD risk factors here assessed. The prevalence of family history of heart attack, stroke and sudden death was, respectively, $3.1 \%$ (95\% CI 2.0 to 4.2 ), $6.3 \%$ (95\% CI 4.7 to 7.9 ) and $5.6 \%$ (95\% CI 4.1 to 7.1 ), without any difference between males and females ( $p>0.05)$.

Prevalence estimates of current and former smoking were, respectively, $0.9 \%$ (95\% CI 0.3 to 1.5 ) and $3.3 \%$ (95\% CI 2.1 to 4.4 ), without any difference between men and women $(\mathrm{p}=0.124)$. Two hundred and fifty-seven students (27.6\%; 95\% CI 24.7 to 30.5) reported regular exposure to other people's smoke. This prevalence was higher in men than in women $(31.5 \%$ vs $23.0 \%$; $\mathrm{p}=0.004)$. The median time of exposure was 1 hour/week (IQR $1-2)$, without any difference between males and females ( $\mathrm{p}=0.976$; table 1$)$. Moreover, the prevalence of physical inactivity (sedentary + exercise) equaled $88.9 \%$ (95\% CI 86.9 to 90.9$)$. Of note, women were more physically inactive than men (93.7\% vs $84.9 \%$; $\mathrm{p}<0.001$; table 2 ).

The median BMI was $23.0 \mathrm{~kg} / \mathrm{m}^{2}$ (IQR 21.0-25.0; table 1), with no difference between men and women $(\mathrm{p}=0.464)$. Overall, $22.1 \%$ (95\% CI 19.4 to 24.8$)$ and $3.9 \%$ (95\% CI 2.7 to 5.1) of students were found with overweight or obesity, respectively (table 2 ). The prevalence of overweight and obesity was higher in women as compared with men $(25.6 \%$ vs $19.1 \%$ and $5.1 \%$ vs $2.8 \%$, respectively; $\mathrm{p}=0.002$ ). The prevalence of abdominal obesity (using IDF criteria) and excess body fat mass was $14.4 \%$ (95\% CI 12.1 to 16.7 ) and $14.5 \%$ (95\% CI 12.2 to 16.8), respectively. A higher number of women had abdominal obesity $(24.4 \%$ vs $5.8 \%$; $\mathrm{p}<0.001)$ and excess body fat mass $(17.2 \%$ vs $12.2 \%$; $\mathrm{p}=0.030)$ than men (table 2).

The median BP was $114 / 71 \mathrm{~mm} \mathrm{Hg}$ (IQR 106/66$122 / 77$; table 1 ) with a significant difference between men and women $(118 / 73$ vs $108 / 69$ mm Hg; $p<0.001)$. The prevalence of suspected prehypertension and hypertension was, respectively, $30.0 \%$ (95\% CI 27.1 to 32.9 ) and $2.8 \%$ (95\% CI 1.7 to 3.9 ), with men being more affected than women ( $42.5 \%$ vs $15.3 \%$; $\mathrm{p}<0.001$, and $4.0 \%$ vs $1.4 \%$; $\mathrm{p}<0.001$, respectively).

\section{Profile of other CVD risk factors}

The prevalence of hazardous alcohol use was estimated at $26.7 \%$ (95\% CI 23.9 to 29.5). The consumption of alcohol at hazardous levels was higher in men than in women $(32.3 \%$ vs $20.2 \%$; $<0.001)$. On the contrary, a higher proportion of women were exposed to household air pollution (assessed through exposure to firewood smoke) than men $(18.6 \%$ vs $13 \%$; $\mathrm{p}=0.018)$. The median time of exposure to firewood smoke was 3 hours/week (IQR 1.3-5), with a significant difference between women and men (4 vs 2 hours/week; $\mathrm{p}<0.001$; table 1 ). Almost 
Table 1 General characteristics of the study population

\begin{tabular}{|c|c|c|c|c|}
\hline Characteristic & $\begin{array}{l}\text { Total } \\
\mathrm{n}=931\end{array}$ & $\begin{array}{l}\text { Male } \\
\mathrm{n}=501\end{array}$ & $\begin{array}{l}\text { Female } \\
\mathrm{n}=430\end{array}$ & $P$ value \\
\hline Age (years), median (IQR) & $23(21-25)$ & $24(21-26)$ & $23(21-25)$ & $<0.001^{*}$ \\
\hline Age (years), n (\%) & & & & $0.004^{*}$ \\
\hline$\leq 20$ & $194(20.8)$ & $90(18.0)$ & $104(24.2)$ & \\
\hline $21-25$ & $516(55.4)$ & $276(55.1)$ & $240(55.8)$ & \\
\hline $26-30$ & $174(18.8)$ & $100(20.0)$ & $74(17.2)$ & \\
\hline $31-35$ & $47(5.0)$ & $35(7.0)$ & $12(2.8)$ & \\
\hline Level of study, n (\%) & & & & 0.453 \\
\hline Undergraduate (in year 3 or less) & $466(50.0)$ & $249(49.7)$ & $217(50.5)$ & \\
\hline Graduate (in year 4 or above) & 465 (49.9) & $252(50.3)$ & $213(49.5)$ & \\
\hline Religion, $\mathrm{n}(\%)$ & & & & 0.142 \\
\hline Christian & $836(89.8)$ & $446(89.0)$ & $390(90.7)$ & \\
\hline Muslim & $72(7.7)$ & $38(7.6)$ & $34(7.9)$ & \\
\hline Other & $23(2.5)$ & $17(3.4)$ & $6(1.4)$ & \\
\hline Ethnic origin, $n(\%)$ & & & & 0.797 \\
\hline Sudano-Sahelian & $73(7.9)$ & $42(8.5)$ & $31(7.2)$ & \\
\hline Sawa & $94(10.2)$ & $47(9.5)$ & $47(11.0)$ & \\
\hline Grassfield & $379(41.0)$ & $202(40.7)$ & $177(41.4)$ & \\
\hline Bantu & $378(40.9)$ & $205(41.3)$ & $173(40.4)$ & \\
\hline Marital status, $\mathrm{n}(\%)$ & & & & 0.134 \\
\hline Single & $869(93.3)$ & $470(93.8)$ & $399(92.8)$ & \\
\hline Divorced & $0(0.0)$ & $0(0.0)$ & $0(0.0)$ & \\
\hline Widow(er) & $2(0.2)$ & $2(0.4)$ & $0(0.0)$ & \\
\hline Married & $35(3.8)$ & $21(4.8)$ & $14(2,8)$ & \\
\hline Concubinage & $25(2.7)$ & $15(3.0)$ & $10(2.4)$ & \\
\hline AUDIT-C score, median (IQR) & $1(0-3)$ & $2(0-4)$ & $1(0-2)$ & $<0.001^{*}$ \\
\hline Second had smoking† (hours/week), median (IQR) & $1(1-2)$ & $1(1-2)$ & $1(1-2)$ & 0.976 \\
\hline $\begin{array}{l}\text { Exposure to firewood smoket (hours/week), median } \\
\text { (IQR) }\end{array}$ & $3(1.3-5)$ & $2(1-3)$ & $4(2-7)$ & $<0.001^{*}$ \\
\hline BMI (kg/m²), median (IQR) & $23(21-25)$ & $23(21-25)$ & $23(21-26)$ & 0.464 \\
\hline Mid-arm circumference (cm), median (IQR) & 27 (26-29) & $28(26-30)$ & $26.5(25-28.3)$ & $<0.001^{*}$ \\
\hline Waist circumference (cm), median (IQR) & 76 (72-81) & $77(74-82)$ & $75(70-80)$ & $<0.001^{\star}$ \\
\hline Hip circumference (cm), median (IQR) & $96(91-101)$ & $95(91-99)$ & $96(91-102)$ & $0.009^{*}$ \\
\hline Waist/hip ratio, median (IQR) & $0.80(0.77-0.84)$ & $0.82(0.79-0.84)$ & $0.78(0.74-0.82)$ & $<0.001^{*}$ \\
\hline Fat mass percentage (\%), median (IQR) & $18(12-26)$ & $13(10-17)$ & $26(21-31)$ & $<0.001^{*}$ \\
\hline Systolic blood pressure (mm Hg), median (IQR) & $114(106-122)$ & $118(112-126)$ & $108(102-115)$ & $<0.001^{*}$ \\
\hline Diastolic blood pressure $(\mathrm{mm} \mathrm{Hg})$, median (IQR) & $71(66-77)$ & $73(67.5-79)$ & $69(64-75)$ & $<0.001^{*}$ \\
\hline
\end{tabular}

${ }^{*} \mathrm{P}<0.05$.

†The total number of participants was 931 (501 males and 430 females) except for secondhand smoking (110 males and 70 females) and exposure to firewood smoke (56 males and 72 females).

AUDIT-C, Alcohol Use Disorder Identification Test-Consumption.

all participants $(99.0 \%$; $95 \%$ CI 98.4 to 99.6$)$ had inadequate fruits and/or vegetables consumption, without significant difference between men and women $(98.8 \%$ vs $99.3 \% ; \mathrm{p}=0.517)$. The prevalence of self-reported anxiety or depression was, respectively, equal to $39.8 \%$ (95\% CI 36.7 to 42.9 ) and $49.2 \%$ (95\% CI 46.0 to 52.4), with women exhibiting higher prevalence estimates than men for both conditions $(\mathrm{p}<0.001$; table 2$)$.

\section{Associations between some of these risk factors}

As depicted in table 3 , age was positively and significantly correlated with the AUDIT-C score $(\rho=0.180 ; p<0.001)$, BMI $(\rho=0.181 ; p<0.001)$, fat mass percentage $(\rho=0.101$; $p=0.002)$, DBP $(\rho=0.098 ; p=0.003)$ and WHR $(\rho=0.205$; $\mathrm{p}<0.001)$. Additionally, the AUDIT-C score was correlated with BMI $(\rho=0.076 ; p=0.021)$, SBP $(\rho=0.157 ; p<0.001)$, DBP $(\rho=0.090 ; p=0.008)$ and WHR $(\rho=0.111 ; p=0.001)$. 
Table 2 Profile of cardiovascular disease risk factors

\begin{tabular}{|c|c|c|c|c|c|c|c|}
\hline \multirow[b]{2}{*}{ Characteristic } & \multicolumn{2}{|c|}{ Total, $\mathrm{n}=931$} & \multicolumn{2}{|c|}{ Male, $n=501$} & \multicolumn{2}{|c|}{ Female, $n=430$} & \multirow[b]{2}{*}{$P$ value } \\
\hline & n (\%) & $95 \% \mathrm{Cl}(\%)$ & n (\%) & $95 \% \mathrm{Cl}(\%)$ & n (\%) & $95 \% \mathrm{Cl}(\%)$ & \\
\hline \multicolumn{8}{|l|}{ Personal history } \\
\hline Self-reported diabetes & $3(0.3)$ & 0.0 to 0.6 & $2(0.4)$ & 0.0 to 0.9 & $1(0.2)$ & 0.0 to 0.6 & 1.000 \\
\hline Another chronic non-communicable disease (asthma) & $15(1.6)$ & 0.8 to 2.4 & $5(1.0)$ & 0.1 to 1.9 & $10(2.3)$ & 0.9 to 3.7 & 0.123 \\
\hline HIV infection (self-reported) & $2(0.2)$ & 0.0 to 0.5 & $0(0.0)$ & I & $2(0.5)$ & 0.2 to 1.2 & 0.213 \\
\hline Either or both of biological parents had a heart attack & $29(3.1)$ & 2.0 to 4.2 & $18(3.6)$ & 2.0 to 5.2 & $11(2.6)$ & 1.1 to 4.1 & 0.365 \\
\hline Either or both of biological parents had stroke & $59(6.3)$ & 4.7 to 7.9 & $29(5.8)$ & 3.7 to 7.8 & $30(7.0)$ & 4.6 to 9.4 & 0.458 \\
\hline Either or both of biological parents had died suddenly & $52(5.6)$ & 4.1 to 7.1 & $24(4.8)$ & 2.9 to 6.7 & $28(6.5)$ & 4.2 to 8.8 & 0.254 \\
\hline $\begin{array}{l}\text { Either or both of biological parents has/had } \\
\text { hypertension }\end{array}$ & $298(32.0)$ & 29.0 to 35.0 & $153(30.5)$ & 26.5 to 34.5 & $145(33.7)$ & 29.3 to 38.2 & 0.299 \\
\hline \multicolumn{8}{|l|}{ Lifestyle } \\
\hline Hazardous alcohol use & $249(26.7)$ & 23.9 to 29.5 & $162(32.3)$ & 28.2 to 36.4 & $87(20.2)$ & 16.4 to 24 & $<0.001^{*}$ \\
\hline Tobacco smoking & & & & & & & 0.124 \\
\hline Former & $31(3.3)$ & 2.1 to 4.4 & $21(4.2)$ & 2.4 to 6.0 & $10(2.3)$ & 0.9 to 3.7 & \\
\hline Current & $8(0.9)$ & 0.3 to 1.5 & $61.2)$ & 0.2 to 2.1 & $2(0.5)$ & 0.2 to 1.2 & \\
\hline Secondhand smoking & $257(27.6)$ & 24.7 to 30.5 & $158(31.5)$ & 27.4 to 35.6 & $99(23.0)$ & 19.0 to 27.0 & $0.004^{*}$ \\
\hline Regular exposure to firewood smoke & $145(15.6)$ & 13.3 to 17.9 & $65(13.0)$ & 10.1 to 15.9 & $80(18.6)$ & 14.9 to 22.3 & $0.018^{*}$ \\
\hline Physical activity & & & & & & & $<0.001^{*}$ \\
\hline Mainly sedentary & $258(27.7)$ & 24.8 to 30.6 & $100(20.0)$ & 16.5 to 23.5 & $158(36.7)$ & 32.1 to 41.3 & \\
\hline Mild exercise & $570(61.2)$ & 58.1 to 64.3 & $325(64.9)$ & 60.7 to 69.1 & $245(57.0)$ & 52.3 to 61.7 & \\
\hline $\begin{array}{l}\text { Eating foods/drinks containing too much sugar one or } \\
\text { more times a day }\end{array}$ & $775(83.2)$ & 80.8 to 85.6 & $423(84.4)$ & 81.2 to 87.6 & $352(81.9)$ & 78.3 to 85.5 & 0.295 \\
\hline Eating oily foods/snacks one or more times a day & $505(54.2)$ & 51.0 to 57.4 & $277(55.3)$ & 50.9 to 59.6 & $228(55.0)$ & 50.3 to 59.7 & 0.489 \\
\hline Eating oily foods/snacks three or more times a week & $483(51.9)$ & 48.7 to 55.1 & $271(54.1)$ & 49.7 to 58.5 & $212(49.3)$ & 44.6 to 54.0 & 0.145 \\
\hline Eating dairy products one or more times a day & $378(40.6)$ & 37.4 to 43.7 & $164(32.7)$ & 28.6 to 36.8 & $214(49.8)$ & 45.1 to 54.3 & $<0.001^{*}$ \\
\hline Eating dairy products three or more times a week & $550(59.1)$ & 55.9 to 62.3 & $281(56.1)$ & 51.7 to 60.4 & $269(62.6)$ & 58.0 to 67.2 & $0.045^{\star}$ \\
\hline $\begin{array}{l}\text { Eating deep fried foods or snacks or fast foods three or } \\
\text { more times a week }\end{array}$ & $527(56.6)$ & 53.4 to 59.8 & $294(58.7)$ & 54.4 to 63.0 & $233(54.2)$ & 49.5 to 58.9 & 0.168 \\
\hline Eating meat and/or poultry two or more times daily & $299(32.1)$ & 29.1 to 35.1 & $143(28.5)$ & 24.5 to 32.4 & $156(36.3)$ & 31.7 to 40.8 & $0.012^{*}$ \\
\hline $\begin{array}{l}\text { Not eating at least } 1-2 \text { cups/portions of fruits one or } \\
\text { more times a day (inadequate fruits consumption) }\end{array}$ & $861(92.5)$ & 90.8 to 94.2 & $472(94.2)$ & 92.1 to 96.2 & $389(90.5)$ & 87.7 to 93.3 & $0.031^{*}$ \\
\hline $\begin{array}{l}\text { Not eating at least } 2-3 \text { cups of vegetables one or more } \\
\text { times a day (inadequate vegetables consumption) }\end{array}$ & $909(97.6)$ & 96.6 to 98.6 & $486(97.0)$ & 95.5 to 98.5 & $423(98.4)$ & 97.2 to 99.6 & 0.171 \\
\hline Inadequate fruits and vegetables consumption & $922(99.0)$ & 98.4 to 99.6 & $495(99.8)$ & 99.4 to 100.0 & 427 (99.3) & 98.5 to 100.0 & 0.517 \\
\hline \multicolumn{8}{|l|}{ Anthropometric parameters and blood pressure } \\
\hline Body mass index $\left(\mathrm{kg} / \mathrm{m}^{2}\right)$ & & & & & & & $0.002^{*}$ \\
\hline Underweight $(<18.5)$ & $45(4.8)$ & 3.4 to 6.2 & $18(3.6)$ & 1.9 to 5.2 & $27(6.3)$ & 4.0 to 8.6 & \\
\hline Normal (18.5-24.9) & $644(69.2)$ & 66.2 to 72.2 & $373(74.5)$ & 70.7 to 78.3 & $271(63.0)$ & 58.4 to 67.6 & \\
\hline Overweight (25-29.9) & $206(22.1)$ & 19.4 to 24.8 & $96(19.1)$ & 15.7 to 22.5 & $110(25.6)$ & 21.5 to 29.7 & \\
\hline Obesity $(\geq 30)$ & $36(3.9)$ & 2.7 to 5.1 & $14(2.8)$ & 1.4 to 4.2 & $22(5.1)$ & 3.0 to 7.2 & \\
\hline
\end{tabular}


Table 2 Continued

\begin{tabular}{|c|c|c|c|c|c|c|c|}
\hline \multirow[b]{2}{*}{ Characteristic } & \multicolumn{2}{|c|}{ Total, $\mathrm{n}=931$} & \multicolumn{2}{|c|}{ Male, $n=501$} & \multicolumn{2}{|c|}{ Female, $n=430$} & \multirow[b]{2}{*}{$P$ value } \\
\hline & n (\%) & $95 \% \mathrm{Cl}(\%)$ & n (\%) & $95 \% \mathrm{Cl}(\%)$ & n (\%) & 95\% Cl (\%) & \\
\hline \multicolumn{8}{|l|}{ Abdominal obesity using WC } \\
\hline IDF criteria (>90/80 cm for men/women) & $134(14.4)$ & 12.1 to 16.7 & $29(5.8)$ & 3.7 to 7.8 & $105(24.4)$ & 20.3 to 28.5 & $<0.001^{*}$ \\
\hline $\begin{array}{l}\text { Abdominal obesity using WHR }(\geq 0.9 / 0.85 \text { for men/ } \\
\text { women) }\end{array}$ & $63(6.8)$ & 5.2 to 8.4 & $19(3.8)$ & 2.1 to 5.5 & $44(10.2)$ & 7.3 to 13.1 & $<0.001^{*}$ \\
\hline Systolic blood pressure & & & & & & & $<0.001^{*}$ \\
\hline Normal $(90-129 \mathrm{~mm} \mathrm{Hg})$ & $671(72.1)$ & 69.2 to 75.0 & $293(58.5)$ & 54.2 to 62.8 & $378(87.9)$ & 84.8 to 91.0 & \\
\hline Prehypertension (120-139mm Hg) & $245(26.3)$ & 23.5 to 29.1 & $195(38.9)$ & 34.6 to 43.2 & $50(11.6)$ & 8.6 to 14.6 & \\
\hline Hypertension ( $\geq 140 \mathrm{~mm} \mathrm{Hg}$ ) & $15(1.6)$ & 0.8 to 2.4 & $13(2.6)$ & 1.2 to 4.0 & $2(0.2)$ & 0.0 to 0.6 & \\
\hline Diastolic blood pressure & & & & & & & $<0.001^{*}$ \\
\hline $\begin{array}{l}\text { Suspected prehypertension (SBP } 120-139 \text { or DBP } \\
80-89 \mathrm{~mm} \mathrm{Hg} \text { ) }\end{array}$ & $279(30.0)$ & 27.1 to 32.9 & $213(42.5)$ & 38.2 to 46.8 & $66(15.3)$ & 11.9 to 18.7 & $<0.001^{*}$ \\
\hline Suspected hypertension (SBP $\geq 140$ or $\mathrm{DBP} \geq 90 \mathrm{~mm} \mathrm{Hg}$ ) & $26(2.8)$ & 1.7 to 3.9 & $20(4.0)$ & 2.3 to 5.7 & $6(1.4)$ & 0.3 to 2.5 & $<0.001^{*}$ \\
\hline
\end{tabular}

${ }^{\star} \mathrm{P}<0.05$.

DBP, diastolic blood pressure; IDF, International Diabetes Federation; SBP, systolic blood pressure; WC, waist circumference; WHR, waist to hip ratio.

Moreover, BMI was correlated with SBP $(\rho=0.203$; $\mathrm{p}<0.001)$, DBP $(\rho=0.103 ; p=0.003)$, fat mass percentage $(\rho=0.585 ; p<0.001)$ and WHR $(0.264 ; p<0.001)$.

\section{DISCUSSION}

\section{Summary of main findings}

This study conducted among a population of young adult university students revealed a high prevalence of some major CVD risk factors. The following prevalence estimates were recorded: $3.1 \%$ for family history of heart attack, $6.3 \%$ for family history of stroke, $5.6 \%$ for family history of sudden death, $32.0 \%$ for family history of hypertension, $16.1 \%$ for family history of diabetes, $26.7 \%$ for hazardous alcohol drinking, $4.2 \%$ for smoking (current \& former), $27.6 \%$ for secondhand smoking, $15.6 \%$ for regular exposure to firewood smoke, $88.9 \%$ for physical inactivity, $39.8 \%$ for self-reported anxiety, $49.2 \%$ for self-reported depression, $99.0 \%$ for inadequate fruits and/or vegetables consumption,

Table 3 Correlation between continuous parameters

\begin{tabular}{|c|c|c|c|c|c|c|c|}
\hline Parameter & & Age & AUDIT-C & BMI & SBP & DBP & Fat $\%$ \\
\hline \multirow[t]{2}{*}{ Age } & Rho $(\rho)$ & 1.000 & 0.180 & 0.181 & 0.040 & 0.098 & 0.101 \\
\hline & $p$ & I & $<0.001$ & $<0.001$ & 0.222 & 0.003 & 0.002 \\
\hline AUDIT-C & $p$ & $<0.001$ & / & 0.021 & $<0.001$ & 0.006 & 0.095 \\
\hline BMI & Rho $(\rho)$ & 0.181 & 0.078 & 1.000 & 0.203 & 0.103 & 0.585 \\
\hline SBP & $p$ & 0.222 & $<0.001$ & $<0.001$ & / & $<0.001$ & $<0.001$ \\
\hline \multirow[t]{2}{*}{ DBP } & Rho $(\rho)$ & 0.098 & 0.090 & 0.103 & 0.723 & 1.000 & -0.060 \\
\hline & $\mathrm{p}$ & 0.003 & 0.006 & 0.002 & $<0.001$ & / & 0.065 \\
\hline Fat $\%$ & Rho $(\rho)$ & 0.101 & -0.055 & 0.585 & 0.192 & -0.060 & 1.000 \\
\hline
\end{tabular}

AUDIT-C, Alcohol Use Disorder Identification Test-Consumption; BMI, bodymass index; DBP, diastolic blood pressure; SBP, systolic blood pressure; WHR, waist to hip ratio. 
$22.1 \%$ for overweight, $3.9 \%$ for obesity, $14.4 \%$ for abdominal obesity, $14.5 \%$ for excess fat mass, $30.0 \%$ for suspected prehypertension and $2.8 \%$ for suspected hypertension. Men had higher prevalence estimates of hazardous alcohol drinking, secondhand smoking, prehypertension and hypertensives than women, while women were more physically inactive, overweight or obese, or had more abdominal obesity and excess fat mass than men. Moreover, SBP and DBP seemed to increase with age, the AUDIT-C score and the BMI.

\section{Comparisons with similar studies, implications and future work}

The prevalence of hazardous alcohol drinking that was recorded in this study $(26.7 \%)$ is lower than the $31.7 \%$, $32.8 \%, 42.5 \%, 26 \%-45 \%$ and $51.9 \%$, respectively, reported from university students in Uganda, Ethiopia, Cameroon, Tanzania and Kenya. ${ }^{25-29}$ Clearly, hazardous alcohol drinking is taking epidemic proportions among younger populations, which will have serious consequences on CVD occurrence, liver cirrhosis and other related health threats. ${ }^{3830}$

The $2.2 \%$ and $3.5 \%$ prevalence of tobacco smoking, respectively, found in Uganda and Somaliland, ${ }^{26} 31$ mirrors the $4.2 \%$ (former and current smoking) reported in this study, though lower than the $29.5 \%$ and $32.5 \%$ reported from Ethiopia and Cameroon. ${ }^{32}{ }^{33}$ The $0.9 \%$ prevalence estimate of current tobacco smoking from the present study resembles that from Mandengue et al at the University of Douala (Cameroon), around $0.6 \%{ }^{25}$ It is possible that the study participants may have underestimated their tobacco consumption, perhaps being aware of its high negative effects, especially towards CVD occurrence. ${ }^{38}$ Tobacco smokers should be helped and accompanied to stop smoking. In this regard, electronic cigarettes have been proposed as a valuable strategy especially in sub-Saharan Africa, but the topic remains an area of huge controversy. ${ }^{34}$

There is sufficient evidence pointing air pollution as a major risk factor for CVD. Feigin $e t$ al showed that $29.9 \%$ of the global burden of stroke was attributable to air pollution. ${ }^{35}$ Although all components of air pollution could not be assessed in this study, it was found that $27.6 \%$ and $15.6 \%$ of participants were exposed to tobacco and firewood smokes, respectively. These are very high rates, which need to be addressed and mitigated. Accordingly, restrictive legislations towards tobacco smoking in public places need to be adopted and effectively applied, and those who violate these laws should be severely punished. Furthermore, people should be counselled on the negative effects of tobacco and firewood smokes, as well as other pollutants.

The prevalence of obesity equaled $4.1 \%$ at the University of Douala (Cameroun) in $2011^{25}$; likewise, a Nigerian study in two universities obtained a rate of $6 \%$ in $2012,{ }^{36}$ comparable to the $3.9 \%$ rate figured out from this study. By contrast, lower rates of overweight (9\%-13\%) were observed among young adults in other parts of
sub-Saharan Africa, ${ }^{26} 31$ 37-39 differing from the $22.1 \%$ recorded in the present study. Moreover, the current prevalence of abdominal obesity (14.4\%) was higher than the $6.5 \%$ found by Mandengue $e t$ al at the University of Douala ${ }^{25}$; on the contrary, it was lower than that from Mogre et al $(31.5 \%)$ among Ghanaian university students. ${ }^{38}$ Concerning excess body fat, it was reported at $7.2 \%$ in Uganda, ${ }^{26}$ almost half equal to what was obtained in the present study $(14.5 \%)$.

This high prevalence of overweight/obesity may be a reflection of an unhealthy diet alongside physical inactivity. In fact, this study revealed that more than two-thirds of participants used to consume too much salty, sugary, oily or deep fried foods/snacks/drinks, contrary to results from Nyombi et al in Uganda showing that only 13\% of students took salt excessively. ${ }^{26}$ Besides, $<1 \%$ of respondents consumed fruits and/or vegetables adequately, concurring with Peltzer and Pengpid who figured out from their international study that $82.8 \%$ of their subjects consumed less than the recommended five servings of fruits and/or vegetables per day. ${ }^{40}$ Similarly, Miller et al demonstrated that consumption of fruit and vegetables is low worldwide (mean 3.76 servings/day), particularly in low-income countries (mean 2.14 servings/day), and mostly explained by low affordability. ${ }^{41}$ By contrast, Otemuyiwa and Adewusi showed that $20 \%-40 \%$ of their students had an adequate fruits and vegetables intake. ${ }^{36}$ Therefore, young adult populations should be educated and encouraged to adopt healthy diet habits, especially by reducing salt, sugar, fats and meat/poultry intake, and consuming at least 1.5-2 portion/cup equivalents of fruits and 2-3 cups of vegetables every day. ${ }^{21}$ It was even shown that benefits towards both non-cardiovascular mortality and total mortality appeared to be maximal at 3-4 servings/day (equivalent to $375-500 \mathrm{~g} /$ day).$^{42}$

Moreover, the prevalence of physical inactivity was very high $(88.9 \%)$ in this study, more than twice what was found at the University of Douala $(41.8 \%)$ and in Somaliland (35.3\%). ${ }^{25} 31$ The importance of physical activity is no more a topic of debate. Actually, a regular moderate to vigorous-intensity physical exercise decreases substantially the risk of, but not limited to, coronary heart disease, stroke, hypertension and diabetes mellitus. ${ }^{43}$ Lear et al showed that individuals from low-income, middle-income and high-income countries exhibited a lower risk of mortality and CVD events when practicing higher recreational and non-recreational physical activity, pointing the increase in physical activity as a simple, widely applicable and low cost global strategy which could reduce remarkably CVD and deaths. ${ }^{44}$ Therefore, sustainable actions should be undertaken to help younger-aged adult populations engage in the practice of a regular and efficacious physical activity to reduce the present or future likelihood of CVD occurrence, as well as other chronic non-communicable diseases.

The prevalence of family history of heart attack, stroke and sudden death was $3.1 \%, 6.3 \%$ and $5.6 \%$, respectively. Furthermore, a family history of hypertension 
and diabetes was, respectively, reported among $32.0 \%$ and $16.1 \%$ of respondents, which concurs with results from Mandengue et al $(34.6 \%$ and $30 \%){ }^{25}$ This is an indirect reflection of the prevalence of these diseases in the Cameroonian adult population, especially for hypertension which was shown at $29.7 \%$ in a recent nationwide study. ${ }^{45}$ The prevalence of suspected hypertension was $2.8 \%$, lower than the $6.4 \%, 7.7 \%, 12.9 \%$ and $14 \%$, respectively, reported by Ali et al in Somaliland, ${ }^{31}$ Tadesse and Alemu in Ethiopia, ${ }^{46}$ Mandengue et al in Douala-Cameroon ${ }^{25}$ and Nyombi et al in Uganda. ${ }^{26}$ However, it is worth mentioning that the prevalence of suspected prehypertension was high at $30.0 \%$, calling for specific interventions to be put in place among these students to reduce their BP levels as they might be at high risk of shifting towards hypertensives in the near future. ${ }^{24} 47$ According to the present results, this could be attained by a reduction in BMI and amount of alcohol consumed, considering the positive correlation observed between SBP/DBP and BMI as well as the AUDIT-C score.

\section{Strengths and limitations}

Noteworthy, this study should be interpreted in the context of some limitations. First, as the questionnaire was self-administered, there were no means to objectively confirm each of the participants' declarations; hence, it may have introduced some information bias with consequential underestimation or overestimation of certain estimates. Second, due to lack of funding, CVD risk factors that request morphological or laboratory explorations were not assessed. Third, only educated participants, selected from only one university institution were included in this study; besides, they were recruited on a consecutive rather than a random basis. Consequently, the study population's representativeness, and the generalisation of results to the entire young adult-aged population of Cameroon could be questionable. Despite these weaknesses, it is worth mentioning that the University of Yaoundé $\mathrm{I}$ is the biggest academic institution in Cameroon; it gathers the country's young adult-aged diversity, with students coming from different backgrounds and from all over the country. In addition, the research team made no distinction/restriction when approaching potential participants to invite them; it is therefore hypothesised that those who did not participate may have had similar characteristics than those who participated. Additionally, rigorous methodology and statistical procedures were applied in this study to answer the research questions.

\section{CONCLUSION}

This study revealed a high prevalence estimate of major CVD risk factors in young adult-aged populations living in Yaoundé, Cameroon. Therefore, specific interventions should be designed and implemented in this population; if not, the burden of CVD could be on sharp increase in the near future, occurring even at younger ages. Accordingly, these young populations should be encouraged and accompanied to practice physical activity, eat healthily, and stop or avoid smoking and/or hazardous alcohol consumption. Moreover, further prospective studies are warranted, which shall help in predicting the overall risk of CVD in young-aged sub-Saharan Africans.

\section{Author affiliations}

${ }^{1}$ Department of Public Health, Faculty of Medicine and Biomedical Sciences of the University of Yaoundé I, Yaoundé, Cameroon

${ }^{2}$ Department for the Control of Disease, Epidemics and Pandemics, Ministry of Public Health, Yaoundé, Cameroon

${ }^{3}$ HIV Care Unit, Ngaoundéré Regional Hospital and Regional Technical Group for the fight against HIV/AIDS, Adamawa Regional Delegation, Ministry of Public Health,

Ngaoundere, Cameroon

${ }^{4}$ Department of Epidemiology and Public Health, Centre Pasteur of Cameroon, Yaoundé, Cameroon

${ }^{5}$ School of Public Health, Faculty of Medicine, University of Paris Sud XI, Le Kremlin Bicêtre, France

${ }^{6}$ Kousseri Regional Hospital, Far-North Regional Delegation, Ministry of Public Health, Kousseri, Cameroon

${ }^{7}$ Lafe-Baleng Divisional Health Centre, Western Regional Delegation, Ministry of Public Health, Bafoussam, Cameroon

${ }^{8}$ Regional Technical Group of the Expanded Program on Immunization, Far-North Regional Delegation, Ministry of Public Health, Maroua, Cameroon

${ }^{9}$ Department of Medicine, University of Cape Town and Groote Schuur Hospital, Cape Town, South Africa

${ }^{10} \mathrm{Centre}$ for Research on Filariasis and other Tropical Diseases, Yaoundé, Cameroon

Acknowledgements We are grateful the Rectorate of the University of Yaoundé I who authorised this study, and to all those who voluntarily participated in this study. Additionally, we thank Dr Emmanuel Armand Kouotou, Dr Pierre Alain Ndzengue Ngono, Dr Hebert Donald Fosso Tene, Dr Francial Terrenstra Nang, Dr Dominic Leandry Angong Wouna, Mr Jean Jacques Baye Yomkil and Mr Suzel Valère Tagatsi Tala for their help in collecting the data and/or reviewing the manuscript.

Contributors JRN, FKA, JJN and JK conceived and designed the study. SJP, JRN, BSK and DNT collected the data. JRN, BSK, JJB and JJN analysed and interpreted the data. JRN wrote the first draft of the manuscript. JJB, FKA, JK, SJP, BSK, JJN, DNT and STN reviewed and revised the manuscript. All authors approved the final version of the manuscript. JRN is the guarantor of the study.

Funding The authors have not declared a specific grant for this research from any funding agency in the public, commercial or not-for-profit sectors.

Competing interests None declared.

Patient consent for publication Not required.

Provenance and peer review Not commissioned; externally peer reviewed.

Data availability statement Data are available upon reasonable request. All data relevant to the study are included in the article or uploaded as supplementary information.

Open access This is an open access article distributed in accordance with the Creative Commons Attribution Non Commercial (CC BY-NC 4.0) license, which permits others to distribute, remix, adapt, build upon this work non-commercially, and license their derivative works on different terms, provided the original work is properly cited, appropriate credit is given, any changes made indicated, and the use is non-commercial. See: http://creativecommons.org/licenses/by-nc/4.0/.

ORCID iDs

Jobert Richie Nansseu http://orcid.org/0000-0001-6155-235X

Jean Joel Bigna http://orcid.org/0000-0001-8018-6279

\section{REFERENCES}

1 World Health Organization. WHO | World Heart Day [Internet]. WHO, 2018. Available: http://www.who.int/cardiovascular_diseases/worldheart-day/en/ [Accessed 26 Jan 2019].

2 World Health Organization. Cardiovascular diseases (CVDs) [Internet], 2017. Available: https://www.who.int/news-room/fact-sheets/detail/ cardiovascular-diseases-(cvds) [Accessed 26 Jan 2019]. 
3 Vos T, Abajobir AA, Abate KH, et al. Global, regional, and national incidence, prevalence, and years lived with disability for 328 diseases and injuries for 195 countries, 1990-2016: a systematic analysis for the global burden of disease study 2016. The Lancet 2017;390:1211-59.

4 Naghavi M, Abajobir AA, Abbafati C, et al. Global, regional, and national age-sex specific mortality for 264 causes of death, 19802016: a systematic analysis for the global burden of disease study 2016. The Lancet 2017;390:1151-210.

5 World Health Organization. The Atlas of Heart Disease and Stroke [Internet], 2017. Available: http://www.who.int/cardiovascular_ diseases/resources/atlas/en/ [Accessed 20 Aug 2017].

6 Smajlović D. Strokes in young adults: epidemiology and prevention. Vasc Health Risk Manag 2015;11:157-64.

7 Kissela BM, Khoury JC, Alwell K, et al. Age at stroke: temporal trends in stroke incidence in a large, biracial population. Neurology 2012;79:1781-7.

8 Gakidou E, Afshin A, Abajobir AA, et al. Global, regional, and national comparative risk assessment of 84 behavioural, environmental and occupational, and metabolic risks or clusters of risks, 1990-2016: a systematic analysis for the global burden of disease study 2016. The Lancet 2017;390:1345-422.

9 Chu C, Dai Y, Mu J, et al. Associations of risk factors in childhood with arterial stiffness 26 years later: the Hanzhong adolescent hypertension cohort. J Hypertens 2017;35(Suppl 1):S10-15.

10 Laitinen TT, Pahkala K, Venn A, et al. Childhood lifestyle and clinical determinants of adult ideal cardiovascular health: the cardiovascular risk in young Finns study, the childhood determinants of adult health study, the Princeton follow-up study. Int J Cardiol 2013;169:126-32.

11 Noubiap JJ, Essouma M, Bigna JJ, et al. Prevalence of elevated blood pressure in children and adolescents in Africa: a systematic review and meta-analysis. The Lancet Public Health 2017;2:e375-86.

12 Shah RV, Murthy VL, Colangelo LA, et al. Association of fitness in young adulthood with survival and cardiovascular risk: the coronary artery risk development in young adults (cardia) study. JAMA Intern Med 2016;176:87-95.

13 Yano Y, Reis JP, Tedla YG, et al. Racial differences in associations of blood pressure components in young adulthood with incident cardiovascular disease by middle age: coronary artery risk development in young adults (cardia) study. JAMA Cardiol 2017;2:381-9.

14 WHO. New initiative launched to tackle cardiovascular disease, the world's number one killer [Internet]. WHO. Available: http://www.who. int/cardiovascular diseases/global-hearts/Global hearts initiative/ en/ [Accessed 26 Jan 2019].

15 Krejcie RV, Morgan DW. Determining sample size for research activities. Educ Psychol Meas 1970;30:607-10.

16 The Unversity of Yaoundé I. The University of Yaoundé I - About Us [Internet], 2016. Available: http://www.webuy1.uninet.cm/uy1/index. php?option=com_content\&view=article\&id=21\&ltemid=112\&lang=en [Accessed 20 Aug 2017].

17 Bush K, Kivlahan DR, McDonell MB, et al. The audit alcohol consumption questions (AUDIT-C): an effective brief screening test for problem drinking. ambulatory care quality improvement project (ACQUIP). alcohol use disorders identification test. Arch Intern Med 1998;158:1789-95.

18 Bradley KA, Bush KR, Epler AJ, et al. Two brief alcohol-screening tests from the alcohol use disorders identification test (audit): validation in a female Veterans Affairs patient population. Arch Intern Med 2003;163:821-9.

19 World Health Organization. Global Physical Activity Questionnaire World Health Organization. Available: www.who.int/chp/steps/GPAQ EN.pdf?ua=1 [Accessed 14 Feb 2017].

20 American Heart Association. American heart association recommendations for physical activity in adults, 2015. Available: http://www.heart.org/HEARTORG/HealthyLiving/PhysicalActivity/ FitnessBasics/American-Heart-Association-Recommendationsfor-Physical-Activity-in-Adults_UCM_307976_Article.jsp\#. WZkhMennqM8 [Accessed 20 Aug 2017].

21 Centers for Disease Controland Prevention. Adults meeting fruit and vegetable intake recommendations - United States, 2013. Available: https://www.cdc.gov/mmwr/preview/mmwrhtml/mm6426a1.htm [Accessed 9 Aug 2017].

22 World Health Organization. Obesity: preventing and managing the global epidemic. Report of a who consultation. World Health Organ Tech Rep Ser 2000;894:1-253.

23 World Health Organization. Waist circumference and waist-hip ratio: report of a who expert consultation, Geneva, 8-11 December 2008. Geneva, Switzerland: World Health Organization, 2011.
24 Chobanian AV, Bakris GL, Black HR, et al. The seventh report of the joint National Committee on prevention, detection, evaluation, and treatment of high blood pressure: the JNC 7 report. JAMA 2003;289:2560-72

25 Mandengue SH, Bita Fouda AA, Epacka Ewane M, et al. Epidemiologiy of obesity among university students in Douala, Cameroon. Med Sante Trop 2015;25:386-91.

26 Nyombi KV, Kizito S, Mukunya D, et al. High prevalence of hypertension and cardiovascular disease risk factors among medical students at Makerere University College of health sciences, Kampala, Uganda. BMC Res Notes 2016;9:110.

27 Francis JM, Weiss HA, Mshana G, et al. The epidemiology of alcohol use and alcohol use disorders among young people in northern Tanzania. PLoS One 2015;10:e0140041.

28 Gebreslassie M, Feleke A, Melese T. Psychoactive substances use and associated factors among Axum university students, Axum town, North Ethiopia. BMC Public Health 2013;13:693.

29 Atwoli L, Mungla PA, Ndung'u MN, et al. Prevalence of substance use among college students in Eldoret, Western Kenya. BMC Psychiatry 2011;11:34.

30 GBD. 2016 alcohol Collaborators. alcohol use and burden for 195 countries and territories, 1990-2016: a systematic analysis for the global burden of disease study 2016. Lancet 2018;23.

31 Ali M, Yusuf HI, Stahmer J, et al. Cardiovascular risk factors and physical activity among university students in Somaliland. $J$ Community Health 2015;40:326-30.

32 Eticha T, Kidane F. The prevalence of and factors associated with current smoking among College of health sciences students, Mekelle university in northern Ethiopia. PLoS One 2014:9:e111033.

33 Peltzer K, Pengpid S. Tobacco use, beliefs and risk awareness in university students from 24 low, middle and emerging economy countries. Asian Pac J Cancer Prev 2014;15:10033-8.

34 Nansseu JRN, Bigna JJR. Electronic cigarettes for Curbing the Tobacco-Induced burden of noncommunicable diseases: evidence revisited with emphasis on challenges in sub-Saharan Africa. Pulm Med 2016;2016:1-9.

35 Feigin VL, Roth GA, Naghavi M, et al. Global burden of stroke and risk factors in 188 countries, during 1990-2013: a systematic analysis for the global burden of disease study 2013. Lancet Neurol 2016;15:913-24.

36 Otemuyiwa IO, Adewusi SRA. Food choice and meal consumption pattern among undergraduate students in two universities in southwestern Nigeria. Nutr Health 2012;21:233-45.

37 Waswa J. Influence of percieved body image on nutrient intake and nutritional health of female students of Moi university. East Afr $J$ Public Health 2011;8:123-31.

38 Mogre V, Aleyira S, Nyaba R. Misperception of weight status and associated factors among undergraduate students. Obes Res Clin Pract 2015;9:466-74.

39 Nwachukwu DC, Nwagha U, Obikili EN, et al. Assessment of body mass index and blood pressure among university students in, Enugu, South East, Nigeria. Nig J Med 2010;19:148-52.

40 Peltzer K, Pengpid S. Correlates of healthy fruit and vegetable diet in students in low, middle and high income countries. Int $J$ Public Health 2015;60:79-90.

41 Miller V, Yusuf S, Chow CK, et al. Availability, affordability, and consumption of fruits and vegetables in 18 countries across income levels: findings from the prospective urban rural epidemiology (pure) study. Lancet Glob Health 2016;4:e695-703.

42 Miller V, Mente A, Dehghan M, et al. Fruit, vegetable, and legume intake, and cardiovascular disease and deaths in 18 countries (pure): a prospective cohort study. The Lancet 2017;390:2037-49.

43 World Health Organization. Global status report on noncommunicable diseases 2014 "Attaining the nine global noncommunicable diseases targets; a shared responsibility. Geneva, Switzerland: World Health Organization, 2014.

44 Lear SA, Hu W, Rangarajan S, et al. The effect of physical activity on mortality and cardiovascular disease in 130000 people from 17 highincome, middle-income, and low-income countries: the PURE study. The Lancet 2017;390:2643-54.

45 Kingue S, Ngoe CN, Menanga AP, et al. Prevalence and risk factors of hypertension in urban areas of Cameroon: a nationwide population-based cross-sectional study. J Clin Hypertens 2015;17:819-24.

46 Tadesse T, Alemu H. Hypertension and associated factors among university students in Gondar, Ethiopia: a cross-sectional study. BMC Public Health 2014;14:937.

47 Ferrer M, Fernández-Britto JE, Bacallao J, et al. Development of hypertension in a cohort of Cuban adolescents. MEDICC Rev 2015;17:41-7. 